\title{
Incidência e Severidade da Cercosporiose do Cafeeiro em Função do Suprimento de Potássio e Cálcio em Solução Nutritiva*
}

\author{
Daniel G. Júnior ${ }^{1 * *}$, Edson A. Pozza ${ }^{1}$, Adélia A. A. Pozza ${ }^{2}$, Paulo E. Souza ${ }^{1}$, Janice G. Carvalho² \& \\ Alexandre C. Balieiro ${ }^{1}$ \\ ${ }^{1}$ Departamento de Fitopatologia, Universidade Federal de Lavras, Cx. Postal 37, CEP 37200-000, Lavras, MG, fax (35) 3829-1283, \\ e-mail:eapozza@ufla.br; ' Departamento de Ciência do Solo, Universidade Federal de Lavras, Cx. Postal 37, CEP 37200-000, \\ Lavras,MG, e-mail: eapozza@ufla.br
}

(Aceito para publicação em 28/03/2003)

Autor para correspondência: Edson A. Pozza

GARCIA JÚNIOR, D., POZZA, E.A., POZZA, A.A.A, SOUZA, P.E., CARVALHO, J.G. \& BALIEIRO, A.C. Incidência e severidade da cercosporiose do cafeeiro em função do suprimento de potássio e cálcio em solução nutritiva. Fitopatologia Brasileira 28:286-291. 2003.

\section{RESUMO}

O objetivo deste trabalho foi avaliar a incidência e a severidade da cercosporiose causada por Cercospora coffeicola em mudas de cafeeiro (Coffea arabica) cultivar Mundo Novo IAC 379-19, em função do suprimento de $\mathrm{K}$ e Ca em solução nutritiva. Instalou-se o experimento em DIC, com 16 tratamentos, três repetições e duas plantas por repetição. Utilizou-se esquema fatorial 4 x 4 , com quatro doses de $\mathrm{K}(1,3,5$ e $7 \mathrm{mmol} / \mathrm{l})$ e quatro níveis de $\mathrm{Ca}(2,4,6$ e 8 $\mathrm{mmol} / \mathrm{l})$. As mudas foram inoculadas semanalmente, durante 12 semanas, com suspensão de esporos de $C$. coffeicola na concentração de 15.000 conídios/ml. Foram realizadas sete avaliações quinzenais para a obtenção da área foliar total, número total de folhas e número total de lesões de cada planta. Após as avaliações determinou-se a porcentagem de área foliar lesionada e o peso da matéria seca total. A interação K x Ca influenciou a área abaixo da curva de progresso do total de lesões, do número total de folhas e a porcentagem de área foliar lesionada. As doses de $\mathrm{K}$, isoladamente, influenciaram a matéria seca total, a área foliar total e a área abaixo da curva de progresso da incidência. As doses de $\mathrm{Ca}$, isoladamente, influenciaram apenas a área foliar total e a área abaixo da curva de progresso da incidência.

Palavras-chave adicionais: Cercospora coffeicola, nutrição mineral, café, doença.

\section{ABSTRACT}

Incidence and severity of the brown eye spot of coffee according to supply of potassium and calcium in nutrient solution

An experiment was carried out at UFLA to evaluate the incidence and severity of the brown eye spot caused by Cercospora coffeicola in coffee (Coffea arabica) seedlings, in relation to different dosages of $\mathrm{K}$ and $\mathrm{Ca}$ in nutrient solution. The experimental design was completely randomized with 16 treatments, three replicates and two plants per replicate. Treatments were displayed in a $4 \mathrm{x} 4$ factorial scheme, with four levels of $\mathrm{K}(1,3$, 5 and $7 \mathrm{mmol} / \mathrm{l})$ and four levels of $\mathrm{Ca}(2,4,6$ and $8 \mathrm{mmol} / \mathrm{l})$. The seedlings were inoculated, every week, for three months, with a conidial suspension of $C$. coffeicola of 15,000 conidia/ml. Total leaf area, total number of leaves and total injury number were obtained from seven evaluations made every fortnight. After the final evaluations, coffee seedlings were collected, the injured leaf area and the dry matter weight determined. The $\mathrm{K} \mathrm{x} \mathrm{Ca}$ interaction influenced total injury, total number of leaves and percentage of injured leaf area under the disease progress curve. The dosages of $\mathrm{K}$ reduced the total dry matter, the total leaf area and the area under the disease incidence progress curve, while the dosages of $\mathrm{Ca}$ influenced the total leaf area and the area under the disease incidence progress curve.

\section{INTRODUÇÃo}

O Brasil é o maior produtor e exportador mundial de café (Coffea arabica L.). Em 1999, as exportações brasileiras de café totalizaram 1,27 milhões de toneladas (Agrianual, 2001). Para a safra 2001/2002, a produção brasileira de café foi estimada em 1,73 milhões de toneladas de grãos (Anuário Estatístico do Café, 2001). No entanto, com a elevação dos custos de produção, além do crescente aumento na competição do mer-

\footnotetext{
* Parte da dissertação de mestrado do primeiro autor. Universidade Federal de Lavras (2002). Trabalho realizado com apoio do Consórcio Brasileiro de Pesquisa e Desenvolvimento do Café.

**B Bolsista do CNPq
}

cado interno e externo, torna-se necessário eliminar quaisquer fontes de perdas nas lavouras cafeeiras (Matiello \& Almeida, 1997). A deficiência nutricional, o manejo inadequado da lavoura, as pragas e as doenças são os principais responsáveis pela redução da qualidade e da produtividade do cafeeiro.

Dentre as doenças dos cafezais, a cercosporiose causada por Cercospora coffeicola Berkeley \& Cooke pode causar sérios prejuízos no campo, em plantações mal conduzidas e principalmente na formação de mudas no viveiro (Reis et al., 1983; Pozza, 1999). Nas regiões altas do Espírito Santo e Minas Gerais, a partir de 1971, observou-se alta intensidade da mancha-de-olho-pardo com redução de até $30 \%$ no rendimento (Miguel et al., 1975). No viveiro as plantas 
Incidência e severidade da cercosporiose do cafeeiro em função do...

apresentam intensa desfolha, redução no desenvolvimento e raquitismo, tornando-se impróprias ao plantio (FernandezBorrero et al., 1966). A nutrição mineral contribui de maneira significativa para reduzir a severidade dessa doença (Pozza, 1999).

Existem poucos trabalhos relacionando o estado nutricional e a suscetibilidade às doenças do cafeeiro (Fernandez-Borrero et al., 1966; Fernandes, 1988; Pozza, 1999), muito embora existam observações de maior nível de infecção por $C$. coffeicola em lavouras depauperadas por adubações insuficientes (Castaño, 1956; Buitrago \& Fernandez-Borrero, 1982) e deficiências hídricas (Santos et al., 1985; Silva \& Oliveira, 1994). As informações sobre a interação patógeno/ nutrição do hospedeiro e sua relação causal com o nível de dano observado são incipientes e carecem de informações.

Os conhecimentos dos efeitos dos nutrientes minerais sobre a suscetibilidade do cafeeiro à cercosporiose podem auxiliar na elaboração de estratégias de manejo e, consequentemente, reduzir as aplicações de defensivos agrícolas e o impacto ambiental. Portanto, no presente trabalho, procurou-se avaliar o efeito de diferentes níveis de potássio e de cálcio na incidência e na severidade da cercosporiose em mudas de café, cultivadas em solução nutritiva.

\section{MATERIALEMÉTODOS}

O experimento foi implantado em casa de vegetação do Departamento de Fitopatologia da Universidade Federal de Lavras, localizado em altitude de $918 \mathrm{~m}$, latitude sul de $21^{\circ} 14^{\prime}$ e longitude oeste $45^{\circ} 00^{\prime}$.

O delineamento experimental utilizado foi o inteiramente casualizado, com 16 tratamentos, três repetições e duas plantas por parcela. Os tratamentos consistiram de quatro doses de $\mathrm{K}$ (1, $3,5$ e $7 \mathrm{mmol} / \mathrm{l})$ combinadas com quatro doses de $\mathrm{Ca}(2,4,6$ e 8 $\mathrm{mmol} / \mathrm{l})$. O esquema para a análise de variância foi o fatorial $4 \times 4$.

Foram utilizadas mudas de café, cv. Mundo Novo IAC 379-19. A semeadura foi realizada em setembro de 2000, em bandejas contendo areia lavada em ácido clorídrico $(\mathrm{HCl})$ a $10 \%$. Quando encontravam-se no estádio de "orelha-de-onça", em dezembro de 2000, as mudas foram transplantadas para os potes plásticos com as soluções nutritivas.

As soluções nutritivas foram acondicionadas em potes plásticos de 61 , pintados com tinta reflexiva, conectados ao compressor de ar por tubos e mangueiras, para promover a aeração contínua das soluções contidas nos recipientes. As soluções foram calculadas a partir da solução de Hoagland \& Arnon (1950), utilizando-se os seguintes sais: $\mathrm{Ca}\left(\mathrm{NO}_{3}\right)_{2} \cdot 4 \mathrm{H}_{2} \mathrm{O}$, $\mathrm{KNO}_{3}, \mathrm{NaNO}_{3}, \mathrm{Mg}\left(\mathrm{NO}_{3}\right)_{2}, \mathrm{NH}_{4} \mathrm{NO}_{3}, \mathrm{NaH}_{2} \mathrm{PO}_{4}, \mathrm{KH}_{2} \mathrm{PO}_{4}$, $\mathrm{MgSO}_{4} .7 \mathrm{H}_{2} \mathrm{O}, \mathrm{NH}_{4} \mathrm{Cl}, \mathrm{KCl}, \mathrm{CaCl}_{2} \cdot 6 \mathrm{H}_{2} \mathrm{O}, \mathrm{K}_{2} \mathrm{SO}_{4}$. Igualmente em todos os tratamentos, foi adicionado $1 \mathrm{ml} / \mathrm{l}$ da solução estoque de micronutrientes, cuja composição foi: $\mathrm{H}_{3} \mathrm{BO}_{3}(1,85 \mathrm{~g} / \mathrm{l})$; $\mathrm{CuSO}_{4} \cdot 5 \mathrm{H}_{2} \mathrm{O}(0,12 \mathrm{mg} / \mathrm{l}) ; \mathrm{MnSO}_{4} .7 \mathrm{H}_{2} \mathrm{O}(3,96 \mathrm{mg} / \mathrm{l})$; $\left(\mathrm{NH}_{4}\right)_{6} \mathrm{Mo}_{7} \mathrm{O}_{24} \cdot 4 \mathrm{H}_{2} \mathrm{O}(0,088 \mathrm{mg} / \mathrm{l}) ; \mathrm{e} \mathrm{ZnSO}_{4} .7 \mathrm{H}_{2} \mathrm{O}(0,086 \mathrm{mg} / \mathrm{l})$. Também foi adicionado em cada litro de solução nutritiva $1 \mathrm{ml}$ da solução estoque de $\mathrm{Na}_{2} \operatorname{EDTA}(14,84 \mathrm{mg} / \mathrm{l})$ e FeCl $2(10,81 \mathrm{mg} / \mathrm{l})$.

Durante o período de cultivo, completou-se o volume das soluções com água desmineralizada, após redução do nível de água a menos de $1 \mathrm{~cm}$ da borda superior dos potes plásticos. $\mathrm{O}$ pH das soluções nutritivas foi ajustado diariamente com $\mathrm{NaOH}(0,1 \mathrm{~N})$ e $\mathrm{HCl}(0,1 \mathrm{~N})$ para 5,5. A depleção de $\mathrm{K}^{+}$das soluções nutritivas foi determinada no Laboratório de Nutrição de Plantas do Departamento de Ciência do Solo da Universidade Federal de Lavras, por meio de fotometria de chama, de acordo com metodologia adotada por Malavolta et al. (1997). Quando a depleção atingiu $70 \%$ da concentração inicial, todas as soluções foram trocadas por soluções correspondentes.

Foram realizadas inoculações semanais, total de 12, segundo metodologia de Pozza (1999). Para obter o inóculo, foram coletadas no campo, folhas de cafeeiro cv. Catuaí com sintomas da cercosporiose. Após a coleta, as folhas foram submetidas à câmara úmida durante 48 h. Com o auxílio de pincel, foram lavadas com água desmineralizada e a suspensão acondicionada em Becker de vidro. A calibragem da suspensão foi determinada em hemacitômetro.

Antes da inoculação realizou-se a limpeza da superfície foliar com algodão para raspar a cutícula e promover leves ferimentos. Em seguida, aplicou-se a suspensão de conídios com atomizador De Vilbiss $\mathrm{n}^{\circ} 15$, em todas as folhas, das mudas de cafeeiro, até o ponto de escorrimento. Após a inoculação, cada vaso foi coberto com saco plástico por $12 \mathrm{~h}$, para proporcionar condições adequadas de temperatura e umidade para o fungo penetrar.

A área foliar de cada planta foi determinada quinzenalmente por análise não destrutiva, com medidor laser de área foliar (Laser Area Meter CI-203 - CID Incorp.). Após sete avaliações, quando as plantas encontravam-se com oito meses de idade, realizou-se a coleta seguida da determinação da área foliar total e da área foliar lesionada.

A incidência e a severidade da cercosporiose foram avaliadas quinzenalmente, com total de sete avaliações. A incidência foi avaliada pela porcentagem do número de folhas com lesão por planta, dividindo-se o número de folhas lesionadas pelo número total de folhas do hospedeiro, e em seguida multiplicando o resultado por 100. A severidade foi avaliada pela contagem do número total de lesões por planta e pela área foliar lesionada.

A partir da equação para calcular a área abaixo da curva de progresso proposta por Campbell \& Madden (1990), obtevese a área abaixo da curva de progresso para incidência (AACPI), total de lesões (AACPTL) e total de folhas (AACPTF). A severidade foi analisada pela porcentagem de área foliar lesionada (AFL\%), determinada após a última avaliação, a partir do desenho das lesões em folha de transparência, as quais foram mensuradas com o auxílio do programa Image Tool ${ }^{\circledR}($ UTHSCA - E.U.A).

Após o término das avaliações, as folhas, as raízes e os caules foram lavados e acondicionados separadamente em sacos de papel e secos em estufa a $60^{\circ} \mathrm{C}$ até atingirem peso constante. Procedeu-se à pesagem e à moagem da matéria seca total.

A análise de variância assim como as regressões foram realizadas com o programa Sisvar® - versão 4.3 (Build 42). As fontes de variação significativas pelo teste $\mathrm{F}$ foram empregadas 


\section{Garcia Júnior et al.}

para construir os modelos de regressão. Em seguida foram plotadas as curvas e as superfícies de resposta, com seus respectivos cortes. Os pontos de máximo e/ou mínimo foram obtidos a partir da derivada primeira de cada equação, as quais foram igualadas a zero.

\section{RESULTADOSE DISCUSSÃO}

A matéria seca total das mudas de cafeeiro (MST) foi significativamente influenciada pelo $\mathrm{K}$. A maior produção de MST $(6,11 \mathrm{~g} /$ planta) foi obtida com a dose $1 \mathrm{mmol} / \mathrm{l}$. O incremento das doses de $\mathrm{K}$ de 3 para $7 \mathrm{mmol} / \mathrm{l}$ reduziu linearmente a produção de MST (Figura 1).

Santos et al. (1994) estudaram o efeito de doses de K na composição do substrato para formar mudas de cafeeiro e também constataram menor produção de matéria seca da parte aérea das mudas com o aumento das doses de K. De acordo com Marschner (1995) o K, presente em elevadas quantidades nos tecidos vegetais, pode interferir na translocação e na disponibilidade fisiológica do $\mathrm{Mg}$ e do $\mathrm{Ca}$, resultando em desordens metabólicas. Essa interferência possivelmente afetou a MST no presente trabalho.

A área foliar total das mudas (AFT) foi afetada pelas doses de $\mathrm{K}$ e de $\mathrm{Ca}$, mas não pela interação entre ambos os nutrientes. A maior AFT foi obtida com a dose 3,63 mmol/l de $\mathrm{K}$ (Figura 2A). Para o Ca, a maior AFT foi obtida com a dose 4,41 $\mathrm{mmol} / \mathrm{l}$ (Figura 2B). Houve aumento da AFT com o incremento das doses de $\mathrm{K}$ de 1 para 3,63 mmol/1 e de Ca de 2 para 4,41 $\mathrm{mmol} / \mathrm{l}$ (ponto de máximo da função), seguido de redução da AFT (Figura 2A e B).

Baixas concentrações de $\mathrm{Ca}^{2+}$ estimulam a translocação de íons, provavelmente devido ao seu efeito estabilizador da membrana celular e também por estimular o metabolismo respiratório e o transporte de elétrons (Bergmann,1992). No entanto, de acordo com Marschner (1995), altas concentrações de íons $\mathrm{Ca}^{2+}$ inibem a translocação de outros cátions por possuir efeito antagônico aos mesmos, confirmando os resultados obtidos no presente trabalho.

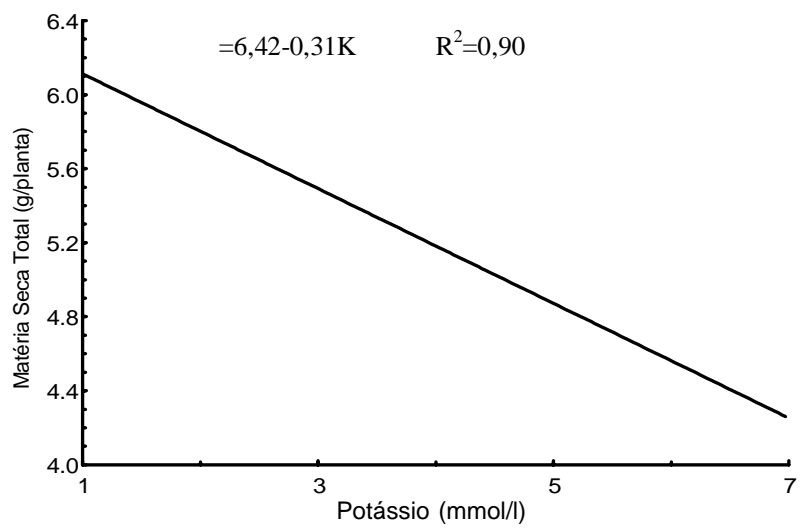

FIG. 1 - Matéria seca total (MST) das mudas de cafeeiro (Coffea arabica) em função das doses de potássio aplicadas em solução nutritiva.
Em estudos sobre o efeito da adubação nitrogenada e potássica na incidência e na severidade da cercosporiose em mudas de cafeeiro, Pozza et al. (2000) não observaram efeito entre o incremento das doses de $\mathrm{K}$ de 3 para $9 \mathrm{mmol} / \mathrm{l}$ e o aumento da área foliar total de mudas de cafeeiro. Esse resultado difere do encontrado no presente trabalho, pois a dose de $\mathrm{Ca}$ permaneceu fixa ( $4 \mathrm{mmol}$ de $\mathrm{Ca}^{2+} / 1$ de solução nutritiva) em todas as doses de $\mathrm{K}(3,5,7$, e $9 \mathrm{mmol} / \mathrm{l})$. Devido a esse fato, nas maiores doses de $\mathrm{K}$ houve baixa absorção de $\mathrm{Ca}$, resultante da competição entre os íons.

A área abaixo da curva de progresso do número total de folhas das mudas de cafeeiro (AACPTF) foi significativamente influenciada pelo incremento das doses de $\mathrm{K}$ e a interação entre os dois nutrientes (Figura 3).

Em todas as doses de K, com exceção da dose $1 \mathrm{mmol} /$ 1, houve aumento na AACPTF com o incremento das doses de Ca. A maior AACPTF (1366.64) foi obtida com a dose 4,07 mmol/ 1 de $\mathrm{Ke} 6 \mathrm{mmol} / \mathrm{l}$ de $\mathrm{Ca}$. Em todas as doses de $\mathrm{Ca}$, com exceção da dose $2 \mathrm{mmol} / \mathrm{l}$ também houve aumento na AACPTF. Estes resultados correspondem ao aumento da área foliar total (AFT) e da produção da matéria seca da parte aérea (MSPA) obtido até a dose $4 \mathrm{mmol} / \mathrm{l}$ de $\mathrm{Ca}$ (Figura 3 ).

Os resultados obtidos para AACPTF em relação à dose $4 \mathrm{mmol} / \mathrm{l}$ de $\mathrm{K}$, confirmam a importância de nutrir a planta
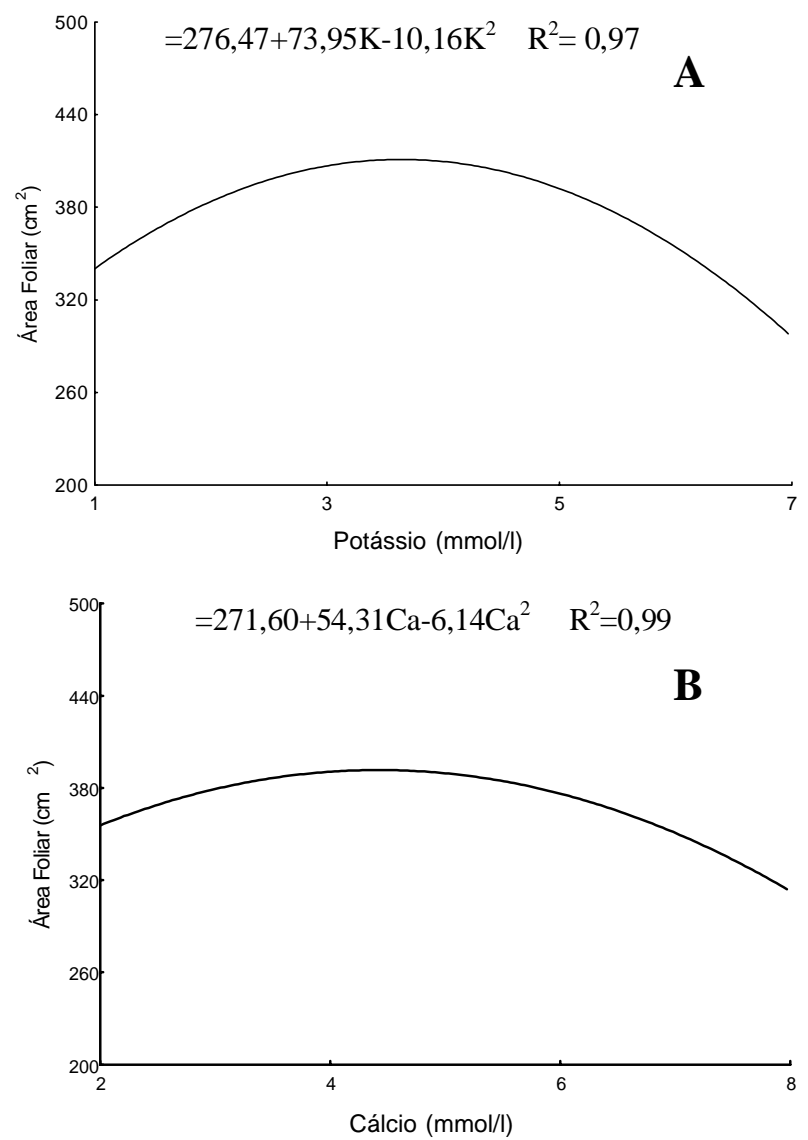

FIG. 2 - Área foliar total $\left(\mathrm{cm}^{2}\right)$ de cafeeiro (Coffea arabica) em função das doses de potássio (A) e das doses de cálcio (B) aplicadas em solução nutritiva. 
Incidência e severidade da cercosporiose do cafeeiro em função do...

adequadamente com esse nutriente. O potássio, quando disponibilizado para a planta em níveis adequados não compete com os demais nutrientes presentes nos tecidos foliares, muitos dos quais são essenciais para o processo de fotossíntese. Além disso, na forma de íons $\mathrm{K}^{+}$é necessário na síntese de proteínas em plantas superiores. Íons $\mathrm{K}^{+}$também estão envolvidos em várias etapas do processo de tradução, incluindo a ligação do tRNA com os ribossomos (Evans \& Wildes, 1971; Wyn Jones et al., 1979).

$\mathrm{O}$ incremento das doses de $\mathrm{K}$ e de $\mathrm{Ca}$ apresentou efeito significativo na AACPI. Em relação ao efeito do K, a menor AACPI $(14,6)$ foi obtida com a dose $4 \mathrm{mmol} / \mathrm{l}$ (Figura 4). Esse resultado está de acordo com aquele obtido para AFT, a qual foi máxima com as doses próximas de $4 \mathrm{mmol} / \mathrm{l}$ de potássio. A menor incidência de $C$. coffeicola favoreceu o aumento da área foliar. Além disso, níveis excessivos desse nutriente interferem na absorção de outros nutrientes, como o Ca e o Mg (Marschner, 1995).

A AACPI decresceu linearmente com o aumento das doses de Ca (Figura 4). Esse resultado confirma a hipótese da competição deste nutriente com o K (Marschner, 1995). No estudo realizado por Pozza et al. (2000), os autores fixaram uma única dose de $\mathrm{Ca}$ em todos os tratamentos e também observaram aumento da AACPI com maiores doses de potássio. A menor AACPI $(14,78)$ foi obtida com a dose máxima de $\mathrm{Ca}$ (Figura 5). O resultado demonstra a importância do fornecimento de Ca no sistema.

A presença de cátions $\mathrm{Ca}^{2+}$ no tecido foliar, respeitando a quantidade ideal de $\mathrm{K}$ no conteúdo celular, inibe drasticamente a ação de enzimas pectolíticas produzidas por muitos parasitas de etiologia fúngica, cuja função é dissolver a lamela média da parede celular. Além disso, na própria lamela média,

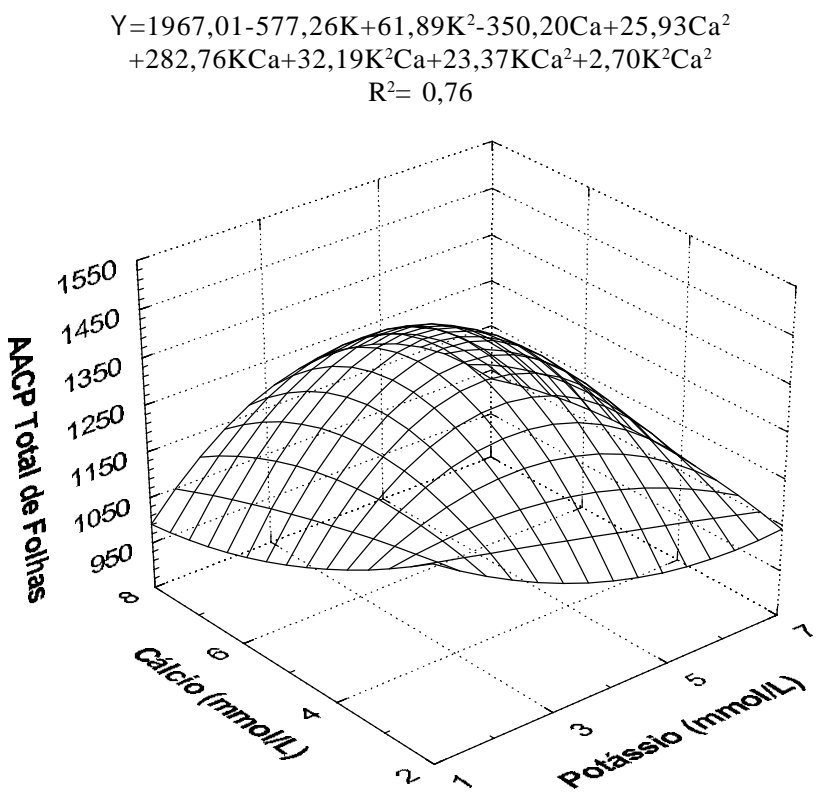

FIG. 3 - Área abaixo da curva de progresso do total de folhas (AACPTF) de cafeeiro (Coffea arabica) em função das doses de potássio e cálcio em solução nutritiva. na superfície externa da membrana plasmática, no retículo endoplasmático e nos vacúolos são encontradas altas concentrações de $\mathrm{Ca}$, comprovando a sua importância para a integridade dos tecidos vegetais (Marschner, 1995).

A área abaixo da curva de progresso do total de lesões (AACPTL) foi significativamente influenciada pelo incremento das doses de $\mathrm{K}$ e de $\mathrm{Ca}$ e também pela interação entre os dois nutrientes (Figura 6).

A menor AACPTL $(213,25)$ foi obtida com as doses 7 $\mathrm{mmol} / \mathrm{l}$ de $\mathrm{Ke}$ 6,35 mmol/l de Ca. Em relação ao K, esse resultado discorda daquele encontrado por Pozza (1999), a qual obteve a menor AACPTL com a menor dose deste nutriente. Provavelmente, o K em altas concentrações, interferiu na absorção do nitrogênio e do Ca pela planta, tornando esta mais suscetível a cercosporiose.

Com exceção da dose $2 \mathrm{mmol} / \mathrm{l}$ de $\mathrm{Ca}$, nas demais doses deste nutriente houve ligeiro aumento na AACPTL com o incremento das doses de K. Para essa dose, a AACPTL diminuiu

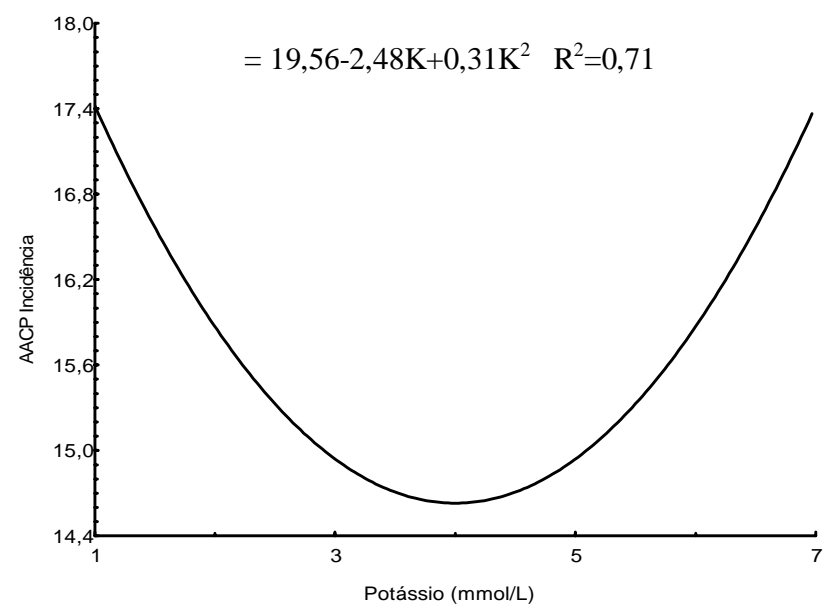

FIG. 4. Área abaixo da curva de progresso da incidência (AACPI) de Cercospora coffeicola em cafeeiro (Coffea arabica) em função de doses de potássio.

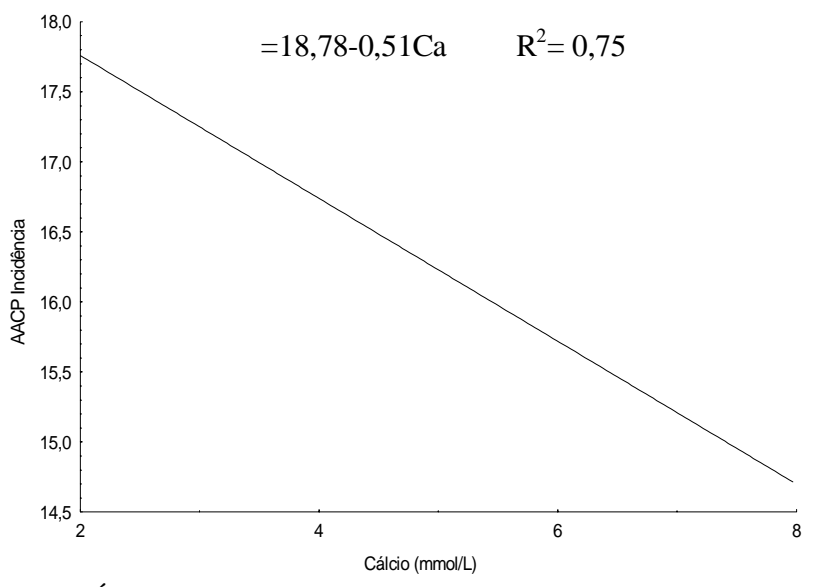

FIG. 5 - Área abaixo da curva de progresso de incidência (AACPI) de Cercospora coffeicola em cafeeiro (Coffea arabica) em função das doses de cálcio em solução nutritiva. 


\section{Garcia Júnior et al.}

com o incremento das doses de $\mathrm{K}$ de 1 a $4,79 \mathrm{mmol} / \mathrm{l}$, aumentando em seguida (Figura 6).

Assim como na AACPI, houve também tendência de reduzir a AACPTL com o aumento das doses de $\mathrm{Ca}$, indicando a importância deste nutriente na constituição da lamela média celular. A redução da AACPI e da AACPTL com o aumento das doses de $\mathrm{K}$ até 4,79 mmol/l justifica-se, pois de acordo com Richardson \& Croughan (1989), toxinas fúngicas induzem o aumento do efluxo de íons $\mathrm{K}^{+}$, reduzindo os teores de $\mathrm{K}$ nos tecidos e nas células infetadas. A partir desta dose, ocorreu inibição competitiva com outros cátions, pois a alta mobilidade do K na planta, favorece essa competição.

A porcentagem de área foliar lesionada (AFL\%) foi influenciada significativamente pelo incremento das doses de $\mathrm{K}$ e de $\mathrm{Ca}$, assim como pela interação entre ambos os fatores, indicando a interferência de um nutriente sobre o outro (Figura 7).

A dose $2 \mathrm{mmol} / \mathrm{l}$ de Ca destacou-se das demais. Nessa dose houve aumento da porcentagem de AFL (Figura 7) e da AACPTL (Figura 6). Isso provavelmente ocorreu devido à menor quantidade do $\mathrm{Ca}$ não ser capaz de competir pelos sítios de absorção com o K, tornando as mudas debilitadas em Ca.

A menor porcentagem de AFL $(0,48 \%)$ foi obtida com as doses de $7 \mathrm{mmol} / \mathrm{l}$ de $\mathrm{K}$ e 6,18 mmol/l de Ca (Figura 7). Essas doses podem ser mais eficientes no manejo da cercosporiose. No entanto, não foram obtidos os melhores resultados referentes às características agronômicas como matéria seca total (MST) para as mesmas doses.

A menor AACPTL também foi obtida com doses de Ke de Ca similares às obtidas para AFL (\%) (7 mmol/l de K e 6,18

\section{$\mathrm{Y}=2850,68-1708,84 \mathrm{~K}+281,09 \mathrm{~K}^{2}-909,39 \mathrm{Ca}+78,87 \mathrm{Ca}^{2}$ $+700,70 \mathrm{KCa}-110,09 \mathrm{~K}^{2} \mathrm{Ca}-61,64 \mathrm{KCa}^{2}+9,44 \mathrm{~K}^{2} \mathrm{Ca}^{2}$ $\mathrm{R}^{2}=0,90$}

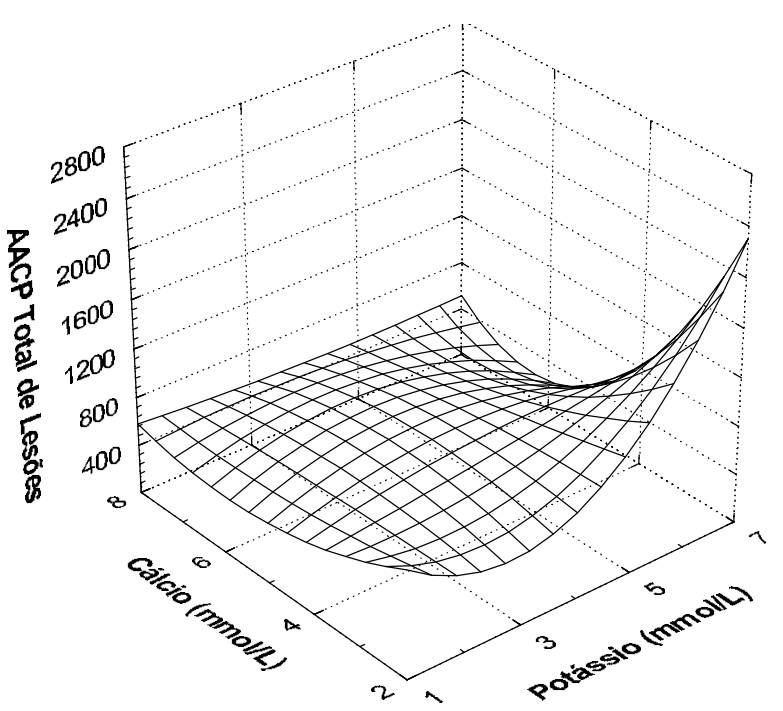

FIG. 6 - Área abaixo da curva de progresso do total de lesões (AACPTL) de Cercospora coffeicola por planta de cafeeiro (Coffea arabica) em função das doses de potássio e cálcio.

$$
\begin{gathered}
\mathrm{Y}=1,13-0,48 \mathrm{~K}+0,22 \mathrm{~K}^{2}-0,21 \mathrm{Ca}+0,04 \mathrm{Ca}^{2}+ \\
0,23 \mathrm{KCa}-0,08 \mathrm{~K}^{2} \mathrm{Ca}-0,03 \mathrm{KCa}^{2}+0,01 \mathrm{~K}^{2} \mathrm{Ca}^{2} \\
\mathrm{R}^{2}=0,87
\end{gathered}
$$

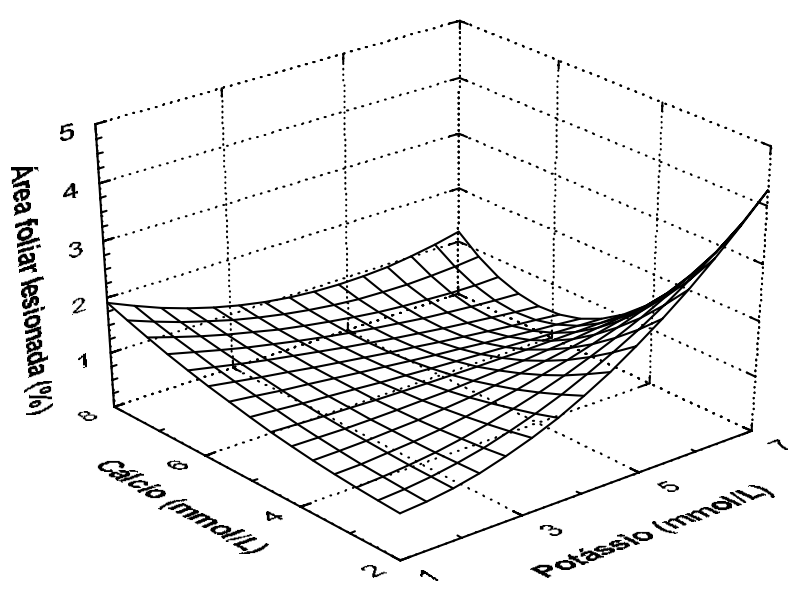

FIG. 7 - Área foliar lesionada (\%) em cafeeiro (Coffea arabica) em função de doses de potássio e cálcio aplicadas em solução nutritiva e também do incremento das doses de cálcio em cada dose de potássio.

mmol/l de Ca). A AACPI, em função das doses de Ca, também apresentou resposta semelhante àquela encontrada para AFL $(\%)$.

\section{REFERÊNCIAS BIBLIOGRÁFICAS}

AGRIANUAL 2001. Anuário da Agricultura Brasileira. São Paulo. 2000.

ANUÁRIO ESTATÍSTICO DO CAFÉ/ COFFEE STATISTIC YEARBOOK. Rio de Janeiro. Coffe Business. 2000/2001.

BERGMANN, W. Nutritional disorders of plants: development, visual and analytical diagnosis. New York. G. Fischer. 1992.

BUITRAGO, J.H.L. \& FERNANDEZ-BORRERO, O. Esporulacion “in vitro" de Cercospora coffeicola Berk \& Cooke. Cenicafé 33:3-14. 1982.

CAMPBELL, C.L. \& MADDEN, L.V. Introduction to plant disease epidemiology. New York. John Wiley \& Sons Inc. 1990.

CASTAÑO A.J.J. Mancha de hierro del cafeto. Boletim Informativo. Cenicafé 82:313-327. 1956.

EVANS, H.J. \& WILDES, R.A. Potassium and its role in enzyme activation. Proceedings of 8th International Potash Institute Colloquia, Bern, 1971. pp.13-39.

FERNANDES, C.D. Efeito de fatores do ambiente e da concentração de inóculo sobre a cercosporiose do cafeeiro (Dissertação de Mestrado). Viçosa. Universidade Federal de Viçosa. 1988.

FERNANDEZ-BORRERO, O., MESTRE, A.M. \& DUQUE, S.L. Efecto de la fertilizacion en la incidência de la mancha de hierro (Cercospora coffeicola) en frutos de café. Cenicafé 47:5-16. 1966.

HOAGLAND, D.R. \& ARNON, D.I. The water - culture method for growing plants without soil. Berkeley. University of California. 1950.

MALAVOLTA, E., VITTI, G.C. \& OLIVEIRA, S.A. Avaliação do estado nutricional das plantas: princípios e aplicações. 2nd ed. Piracicaba. POTAFOS. 1997. 
Incidência e severidade da cercosporiose do cafeeiro em função do...

MARSCHNER, H. Mineral nutrition of higher plants. 2nd ed. London. Academic Press. 1995.

MATIELLO, J.B. \& ALMEIDA, S.R. Controle associado de doenças do cafeeiro. Correio Agrícola 2:25-27. 1997.

MIGUEL, A.E., MASK, Z., MATIELLO, J.B. \& ALMEIDA, S.R. Efeito de fungicidas no controle de Cercospora coffeicola em frutos de café. Resumos $3^{\circ}$ Congresso Brasileiro de Pesquisas Cafeeiras, Curitiba, PR. 1975. pp.18-21.

POZZA, A.A.A. Influência da nutrição nitrogenada e potássica na intensidade da mancha de olho pardo (Cercospora coffeicola Berk. \& Cook.) em mudas de cafeeiro. (Tese de Mestrado). Viçosa. Universidade Federal de Viçosa. 1999.

POZZA, A.A.A., MARTINEZ, H.E.P., POZZA, E.A., CAIXETA, S.L. \& ZAMBOLIM, L. Intensidade da mancha de olho pardo em mudas de cafeeiro em função de doses de $\mathrm{N}$ e de $\mathrm{K}$ em solução nutritiva. Summa Phytopathologica 26:29-33. 2000.

RICHARDSON, M.D. \& CROUGHAN, S.S. Poatassium influence on susceptibility of bermudagrass to Helmintosporium cynodontis toxin. Crop Science 29:1280-1282. 1989.

SANTOS, F.A. de S., MATIELLO, J.B., RIBEIRO, R.W. de C. \& SANTINATO, R. Época de controle da cercosporiose (Cercospora coffeicola) no estado de Pernambuco - Garanhuns. Resumos, $12^{\circ}$ Congresso Brasileiro de Pesquisas Cafeeiras, Caxambu, MG. 1985. pp.182-183.

SANTOS, L.P., CARVALHO, M.M. \& CARVALHO, J.G. Efeitos de doses de nitrato de potássio e esterco de curral na composição do substrato para formação de mudas de cafeeiro (Coffea arabica L.). Ciência e Prática 18:42-48. 1994.

SILVA, S.A. \& OLIVEIRA, C.A. Avaliação da eficiência de fungicidas sistêmicos com a adição de adjuvantes no controle da Cercospora coffeicola (Berk \& Br.) em cafeeiros na região do Alto Paranaíba. Resumos, $20^{\circ}$ Congresso Brasileiro de Pesquisas Cafeeiras, Guarapari, RJ. 1994. pp.11-12.

REIS, G.N., MIGUEL, A.E. \& MATIELLO, J.B. Níveis de adubação em presença e ausência de fungicida cúprico no controle à cercosporiose (Cercospora coffeicola Berk. \& Cook.) do cafeeiro na região cafeeira da Bahia. Anais, $10^{\circ}$ Congresso Brasileiro de Pesquisas Cafeeiras, Poços de Caldas, MG. 1983. pp.101-102.

WYN JONES, R.G., BRADY, C.J. \& SPEIRS, J. Ionic and osmotic relations in plant cells. In: Laidman, D.L. \& Wyn Jones, R.G. (Eds.) Recent advances in the biochemistry of cereals. London: Academic Press, 1979. pp.63-103. 